\title{
Design of Compact Dual-band Fractal Monopole Antenna with Virtually Extended Ground Plane
}

\author{
Mahmood T. Yassen', Mohammed R. Hussan², Hussain A. Hammas², \\ Ali J. Salim ${ }^{1}$ and Jawad K. Ali ${ }^{1}$ \\ ${ }^{1}$ Microwave Research Group, Department of Electrical Engineering, University of Technology, Iraq \\ ${ }^{2}$ Department of Communication Engineering, University of Technology, Iraq \\ *corresponding author, E-mail: jawadkali@ theiet.org
}

\begin{abstract}
Achieving a particular response to serve multiple wireless applications is regarded as the primary demand in our modern age because of the considerable development of the communication devices. In this paper, a compact monopole antenna with reduced ground plane has been suggested to meet the requirements of the dual-band WLAN applications. The antenna miniaturization has been carried out in employing two techniques. Initially, the fractal geometry has been applied to the antenna radiating element. Two-sided Koch fractal curves up to the third iteration have been used to increase the path of electrical current on the surface of the radiating element which is in the form of a square with dimensions. To gain more miniaturization, the antenna ground plane has been further reduced by using different lengths of two open-ended parallel stubs to form a virtually extended ground plane. This supportive technique has been adopted as a tuning means to control the path of the electrical currents exciting the resulting resonances. The proposed antenna and has been printed on an FR-4 substrate with a thickness of $1.6 \mathrm{~mm}$ and 4.4 relative dielectric constant and is fed by $50-\mathrm{ohm}$ microstrip feed line. The resulting antenna dimensions are of about $18.93 \mathrm{~mm} \times$ $18.93 \mathrm{~mm}$. A parametric study has been carried out, and the results reveal that the proposed antenna offers a dual-band performance with a considerable ratio of resonant frequencies covering the existing $2.4 / 5.8 \mathrm{GHz}$ WLAN applications, besides many other communication services. Measured results of a fabricated prototype show the validity of the proposed methodology to design a compact size dualband antenna.
\end{abstract}

\section{Introduction}

The impressive growth in the existing wireless communication systems and services has imposed additional requirements on the related antennas to be miniaturized and multiband [1]. Providentially, fractal geometries, as formalized first by Mandelbrot [2], provide the means to the designers, to achieve compact size microwave antennas, circuits, and components. Fractal geometries have two unique properties, the space-filling, and self-similarity. These features are successfully adopted by the researchers to design highly miniaturized microstrip and printed antennas with dual-band and multiband performance. Also, the space-filling property of many fractal geometries has been successfully applied traditional Euclidean shapes, such as the square, the triangle, and the circle, to produce compact size microwave resonators and filters [3].

Slot, patch and printed dipoles antennas based on fractal curves such as Cantor, Sierpinski, Peano, Koch, Minkowski, and other fractal based structures have paid the attention of the designers to realize miniaturized antennas with multiple resonances for a wide variety of wireless communication applications. In this respect, Cantor fractal geometry and its variants have been reported in [4] to model a dual-band microstrip line fed slot and printed monopole antennas for GSM and 2.4 GHz WLAN bands. Koch fractal and its modifications have become attractive for the designers seeking for producing compact slot and printed monopole antennas for a wide range of multi-services communication applications [5- 9]. Besides, Sierpinski, [1011], and Peano, [12-14], fractal geometries have been successfully applied to generate antenna structures based on Euclidean geometries such as the circle, triangle, and others, to produce dual-band and multiband antennas with a compact size to meet the requirements of the recently available communication services. Moreover, other fractal geometries such as Moore [15], and many others have found their way to be used in the design of reduced size patch, monopole and slot antennas.

On the other hand, the ground plane of the printed monopole antennas is the main part that dominantly governs their overall size. The use of various fractal geometries results in dual-band and multiband printed monopole antennas. To acquire more size reduction of these antennas, their ground planes have been of small size and virtually extended. The extension of the antenna ground plane has been achieved by modifying it such that it is provided with open stubs at its edges. This idea has been successfully 
applied to design compact size coplanar waveguide fed ultrawideband (UWB) monopole antennas [16-17].

In this paper, the performance of Koch fractal-based printed monopole antennas is thoroughly investigated for use in different dual-band and multiband communication applications. The radiating elements of the presented antennas are derived from the typically printed square patch with its sides modified in the form of the 2 nd and the $3 \mathrm{rd}$ iteration Koch fractal curve.

\section{The proposed antenna structure}

The Koch fractal geometry has been adopted, in this paper, to reshape the square patch radiator of the monopole antenna. To demonstrate the generation process of the Koch fractal geometry, the first four steps are shown in Figure 1. The first iteration of replacing a segment with the generator is shown in Figure 1(b).

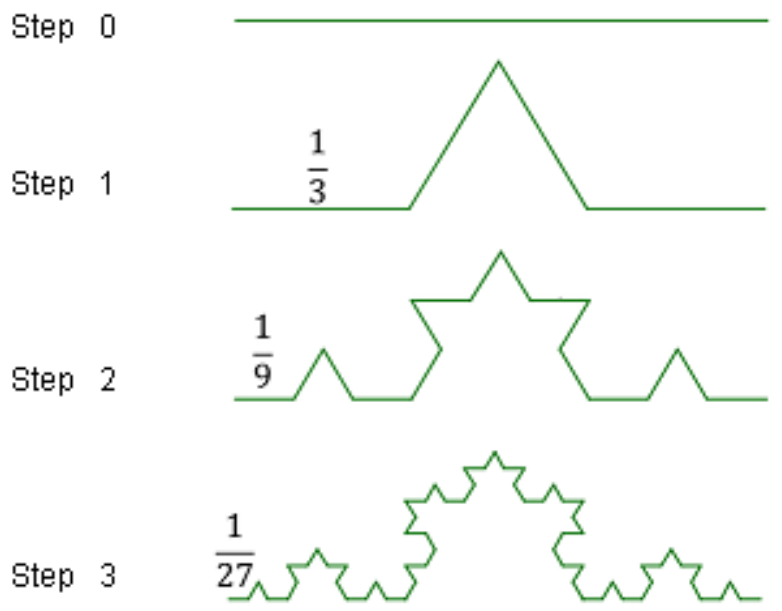

Figure 1: The first four iterations of the Koch fractal curve.

The starting pattern is Euclidean and, therefore, the process of replacing the segment with the generator constitutes the first iteration. The generator is scaled after such that the endpoints of the generator are precisely the same as the starting line segment. In the generation of the actual fractal, the process of replacing every segment with the generator is carried out an infinite number of times. The resulting pre-fractal structure has the characteristic that the perimeter increases to infinity while maintaining the volume occupied. This increase in length decreases the required size occupied by the pre-fractal antenna at resonance. It is found that [2]:

$$
L_{n}=\left(\frac{4}{3}\right) L_{n-1}
$$

where, $L_{\mathrm{n}-1}$ is the length of the $n$th iteration pre-fractal structure. Theoretically, as $n$ goes to infinity, the occupied length gets to infinity. The capability of the resultant structures to expand their lengths in the succeeding iterations is triggering for examining its size reduction means in the antennas and microwave circuit design.
The Koch fractal curve, of the 2nd and the 3rd iterations, is applied to the conventional square radiating element of the printed monopole antenna. The resulting fractal monopole antennas are shown in Figures 2(a) and (b) respectively. These antennas are directly fed with microstrip lines etched on the substrate containing the radiating element while a reduced ground plane is printed on the reverse side of the substrate. The substrate is supposed to be with a relative dielectric constant of 4.4 and thickness of 1.6 $\mathrm{mm}$. The resulting $50 \Omega$ microstrip line has a width of about $3.0 \mathrm{~mm}$.

\section{The antenna design}

Printed monopole antennas, based on the 2nd and the 3rd iteration Koch fractal geometries, have been designed to resonate at $2.4 \mathrm{GHz}$. The layouts of these antennas have been shown in Figure 2, with the substrate parameters and a feed line as described in the previous section. The presented antennas, with the layouts depicted in Figures 2(a) and 2(b), have been modeled and analyzed using the method of moments (MoM) based electromagnetic (EM) simulator IE3D [18]. At the design frequency, the side lengths, corresponding to the 2nd and the 3rd iteration Koch radiating elements, are found to be of about $23 \mathrm{~mm}$ and 19 $\mathrm{mm}$ respectively. By suitable dimension scaling, the side lengths of the antenna radiating elements have to be determined. Observing the impact of the different parameters on the antenna performance, it has been found that the dominant factor in the antenna is the radiating element side length in terms of the guided wavelength $\lambda_{g}$.

$$
\lambda_{g}=\frac{\lambda_{0}}{\sqrt{\varepsilon_{e f f}}}
$$

where $\varepsilon_{\text {eff }}$ is the effective dielectric constant. Then the lower resonant frequency, $f_{\mathrm{r} 1}$, relative to the radiating element side length can be expressed by

$$
f_{r 1}=\frac{c}{3.53 L \sqrt{\varepsilon_{e f f}}}
$$

where $c$ is the speed of light in free space, and $L$ is the radiating element side length. Higher order resonances are attributed to the smaller self-similar structures, as will be seen later.

\section{The antenna performance evaluation}

The monopole antennas with their radiating elements based on the 2nd and the 3rd iteration Koch fractal geometry have been modeled to resonate at $2.4 \mathrm{GHz}$. Figure 2 depicts the layouts of the modeled antennas. For the sake of comparison, the resulting $S_{11}$ responses of the modeled monopole antennas are illustrated together in Figure 3. It is evident that the monopole antenna with 3 rd iteration fractal geometry tends to excite more resonances in the swept frequency range as compared with that based on the 2nd iteration 


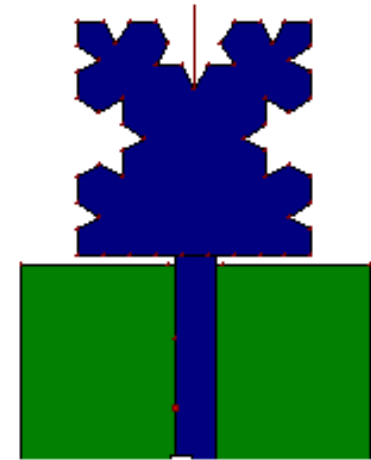

(a)

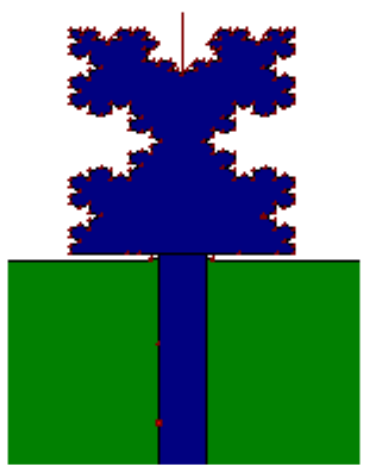

(b)
Figure 2: The layouts of the modeled monopole antennas with (a) 2nd, and (b) 3rd iteration Koch fractal geometry.

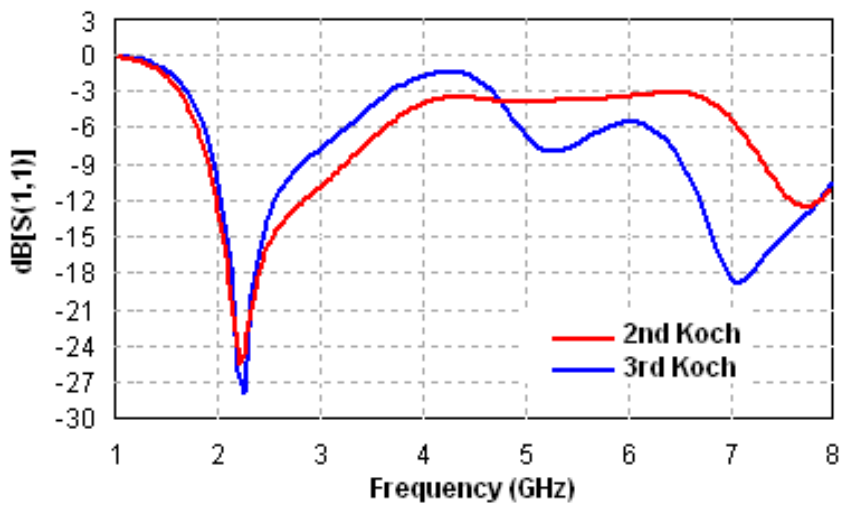

Figure 3: The $S_{11}$ responses of the 2 nd and the 3rd iteration Koch fractal monopole antennas

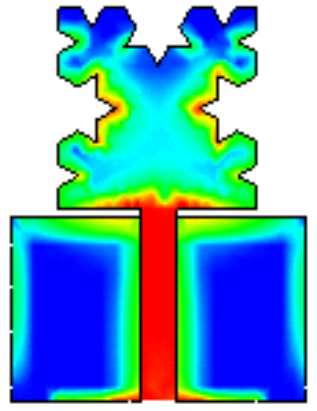

(a)

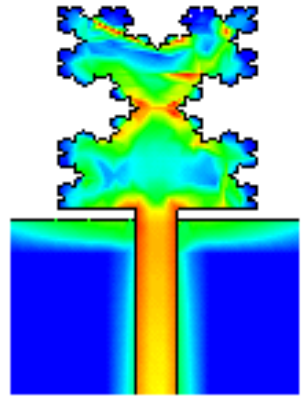

(b)
Figure 4: The surface current distributions on the 2nd and the 3 rd iteration Koch fractal monopole antenna structures.

The current distributions on the surface of the monopole antennas presented in Figures 2(a) and (b) are demonstrated in Figure 4. An impressive result can be drawn from the current distributions of both antennas. The currents are concentrated on the left and the right sides of the antenna radiator while there is almost no current on the upper side. Consequently, the upper sides of both antenna radiating elements can be modified since they have no contribution in the resulting antenna radiation patterns. The modification of the radiating element of the 3rd iteration Koch fractal antenna has a very slight effect on the antenna S11 response as compared with initially modeled antenna shown in Figure 2(b). The results of Figure 5 validate this conclusion. From now on, all the modeled antennas presented in the next sections will be of a modified type as prescribed.

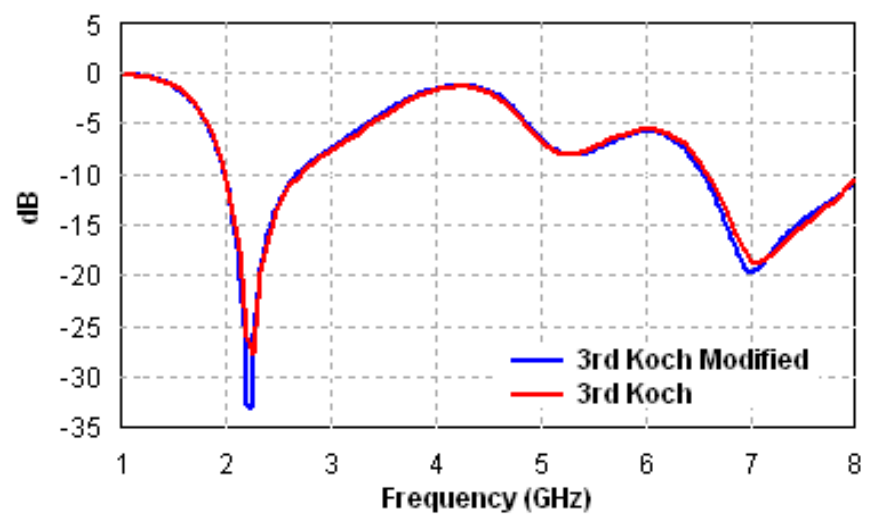

Figure 5: The $S_{11}$ responses of the 3rd iteration Koch fractal monopole antenna and the modified monopole antenna.

The reduction of the antenna size requires the reduction of both the antenna radiating element and the ground plane. Thus, the modification of the monopole radiating element using fractal geometry has an only limited effect. On the other hand, the width of the antenna ground plane has a considerable influence on the antenna performance, and it governs the final antenna size. Besides, reducing the width of the ground plane prevents, to a certain extent, the excitation of resonant bands, because some portions of the radiating elements are shadowed. To handle this issue, another modification has been made on the resulting antenna regarding its ground plane. The antenna ground plane has been virtually extended without the addition of an extra size making the antenna larger. It has been shown that providing the edges of the antenna ground plane with conducting stubs will be practically equivalent to a ground plane extension. Figure 6 illustrates the proposed antennas with modified radiating elements while Figure 6(b) shows the antenna with the modified ground plane.

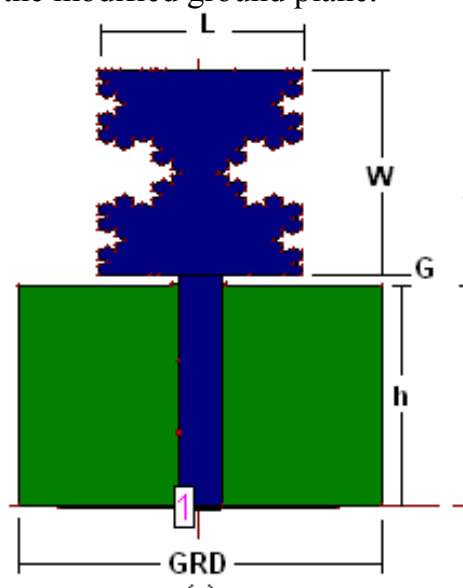

(a)

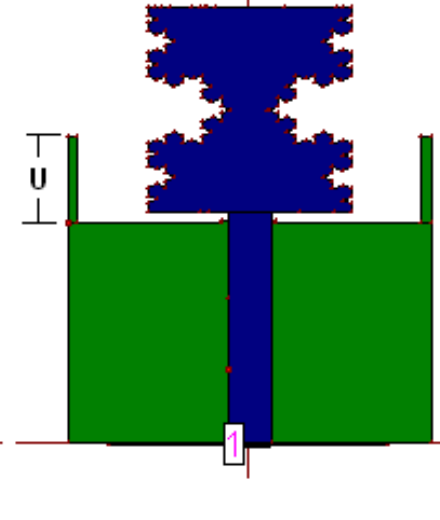

(b)
Figure 6: The layouts of the modeled Koch fractal monopole antennas with (a) typical ground plane and (b) virtually extended ground plane. 


\section{Parametric investigation}

The proposed antenna, as depicted in Figures 6(a) and (b), has many elements that affect its performance. These parameters provide the designer with more degrees of freedom to achieve the design requirements. The most effective parameters will be examined, and its significance on the antenna response will be assessed.

The effect of the variation of the spacing $G$ on the antenna performance has been shown in Figure 7, where G has been varied from 0 to 1.5 in steps of $0.5 \mathrm{~mm}$. The location of the lower resonant band and its center frequency are slightly affected. Anyway, the influence on the upper resonant band is more apparent. As the $G$ increases, the center of the upper resonant band is up shifted while the corresponding bandwidth becomes wider. Above some specific value of $G$, the upper resonant band starts to weaken.

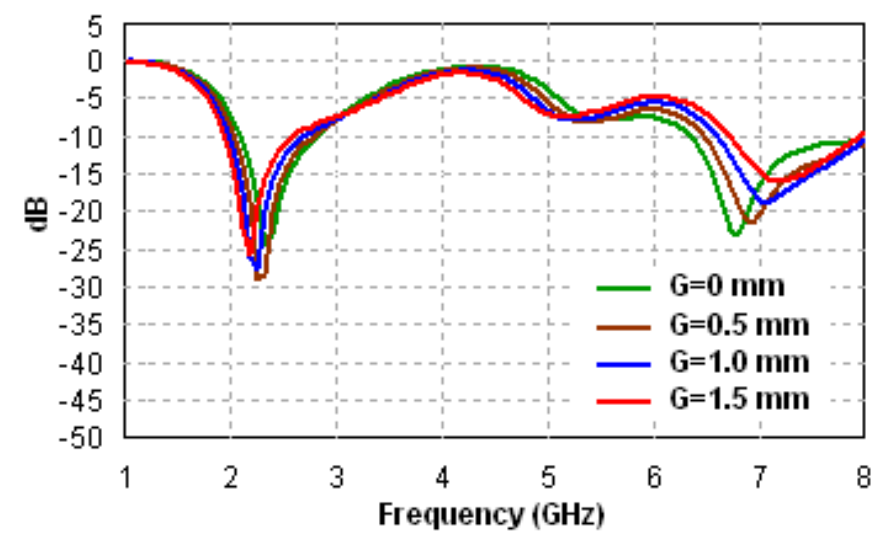

Figure 7: The $S_{11}$ responses of the 3rd iteration Koch fractal monopole antenna of Figure 6(a) with $\mathrm{G}$ as the parameter

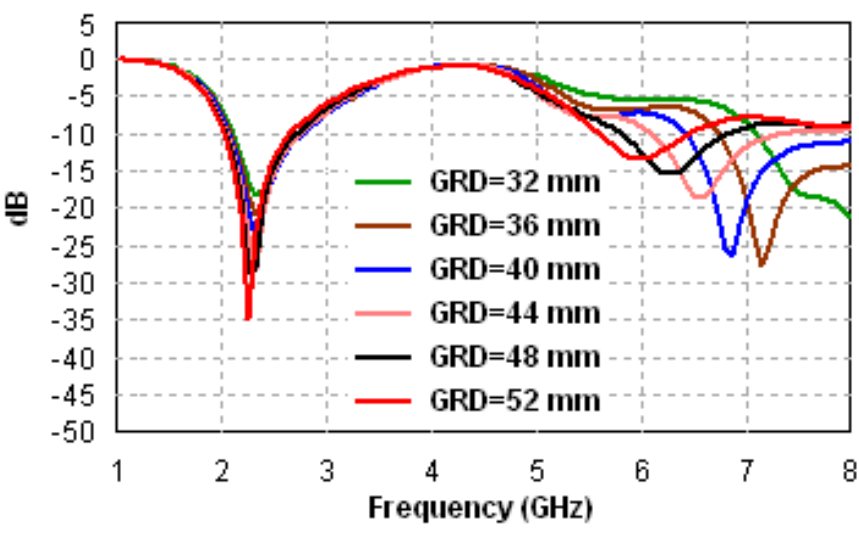

Figure 8: The $S_{11}$ responses of the 3rd iteration Koch fractal monopole antenna of Figure 6(a) with GRD as the parameter

The effect of the variation of the ground plane width GRD on the antenna performance has been shown in Figure 8 keeping the spacing $\mathrm{G}$ unchanged. The lower resonant band has not been affected except for the more strengthened coupling of the band. However, the effect on the upper resonant band is more evident. As the GRD increases, the upper resonant band is considerably affected; its position is shifted down while the corresponding bandwidth becomes narrower. Above some certain value of GRD, the upper resonant band starts to diminish.

The effect of the variation of $\mathrm{G}$ on the antenna shown in Figure 6(b) performance has been shown in Figure 9 with the spacing $\mathrm{G}$ varies from 0 to $1.0 \mathrm{~mm}$ in steps of $0.25 \mathrm{~mm}$. The GRD and $U$ are kept unchanged at $34 \mathrm{~mm}$ and $10 \mathrm{~mm}$ respectively. The position of the center of the lower resonant is less affected as compared with that of the upper band. The variation of the upper resonant band covers a frequency range starting from about 5.25 to $6.0 \mathrm{GHz}$.

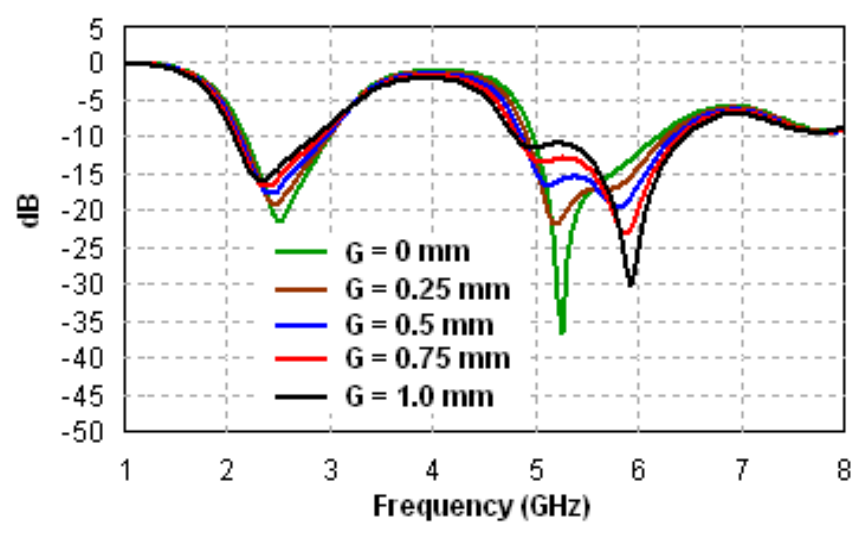

Figure 9: The $S_{11}$ responses of the 3rd iteration Koch fractal monopole antenna of Figure 6(b) with $\mathrm{G}$ as the parameter

The effect of the variation of GRD on the antenna performance has been shown in Figure 10. The antenna ground plane extension $\mathrm{U}$ and the spacing $\mathrm{G}$ are maintained constant at $10 \mathrm{~mm}$ and $1.0 \mathrm{~mm}$ respectively while the ground plane width has been varied from $30 \mathrm{~mm}$ to $40 \mathrm{~mm}$ in steps of $2 \mathrm{~mm}$. As the GRD increases, the lower resonant band is slightly affected; its position is shifted down while the corresponding bandwidth is broadened. On the other hand, the upper resonant band is shifted down in with narrowing bandwidth. However, the variation of the upper resonant band covers a broad frequency range starting from about 5.0 to $6.35 \mathrm{GHz}$.

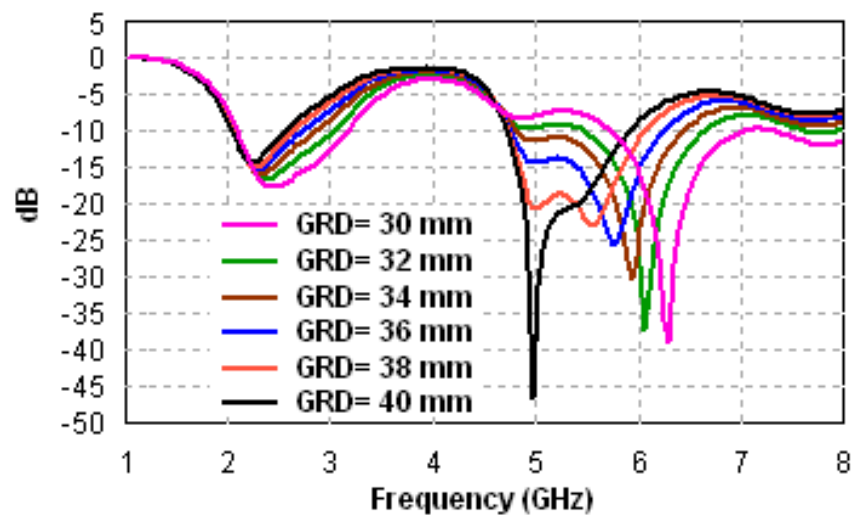

Figure 10: The $S_{11}$ responses of the 3rd iteration Koch fractal monopole antenna of Figure 6(b) with GRD as the parameter. 
The results demonstrated in Figure 11 seem very interesting. The results of the S11 responses of the antenna depicted in of Figure 6(b) with the ground plane width GRD and the spacing $\mathrm{G}$ are kept unchanged at $34 \mathrm{~mm}$ and 0.95 $\mathrm{mm}$ respectively. The increment in $\mathrm{U}$ maintains the dualband resonant performance of the modeled antenna. Although the resulting variation of the first band is slight, however, it is not the case for the upper band. The variation of the upper resonant band covers a broad frequency range starting from 5.0 to $8.0 \mathrm{GHz}$. However, as $\mathrm{U}$ increases, the upper resonant bandwidth increases with its center frequency becomes lower. The position of the lower band is almost maintained but with slightly reduced bandwidth.

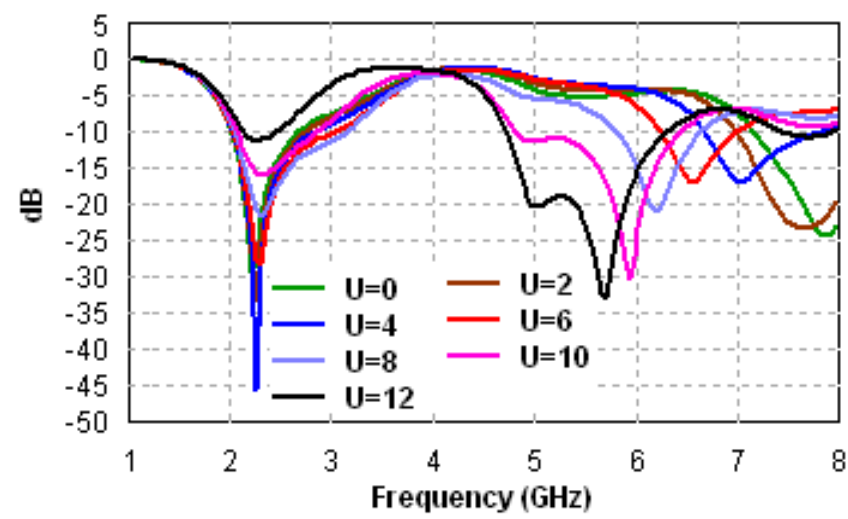

Figure 11: The $S_{11}$ responses of the 3rd iteration Koch fractal monopole antenna of Figure 6(b) with $\mathrm{U}$, (in $\mathrm{mm}$ ), as the parameter.

Above some certain value of $U$, the lower resonant band starts to diminish, and the antenna tends to excite a third resonance within the swept frequency range. In summary, with the tuning of $\mathrm{U}$, the antenna will have an exciting performance with a considerable ratio of the upper to the lower resonant frequencies making it suitable for integration of many dual-band communication services.

The effect of varying the antenna virtual ground extension, depicted in Figure 11, can be better understood with the aid of the current distribution on the surface of the antenna structure at different values of U. For this purpose, two cases are considered; $U=10 \mathrm{~mm}$, and $U=4 \mathrm{~mm}$. Examining Figure 11, it is clear that the antenna offers dualband resonances at $2.4 \mathrm{GHz}$ and $5.8 \mathrm{GHz}$ For the first case, while for the second case; the antenna has dual-band resonances at $2.4 \mathrm{GHz}$ and $7.0 \mathrm{GHz}$. The current distributions, for the two cases, have been simulated at three frequencies including the dual-band resonances of each antenna. The results are demonstrated in Figure 12. Careful investigation of the results of Figure 12 will lead to the following interpretation. At $2.4 \mathrm{GHz}$, both antennas perform equally, and it is clear that there is no effect of the virtually extended ground plane on the first resonant band. The impact of the virtual ground extension seems clearly at the second resonant frequency for each case, at $5.8 \mathrm{GHz}$ for the first case and $7.0 \mathrm{GHz}$ for the second one. For out of the resonance frequencies, at $7.0 \mathrm{GHz}$ for the first case and 5.8 for the latter, the existence of non-propagating mode patterns are apparent in the transmission line feed.

The non-propagating mode pattern indicates high values of voltage standing wave ratio (VSWR) as reported by [19]. The large values of VSWR prevent the excitation of any resonance, and consequently, the required coupling has not been satisfied. The same conclusion can be drawn about other resonances corresponding to the particular virtual ground extensions.
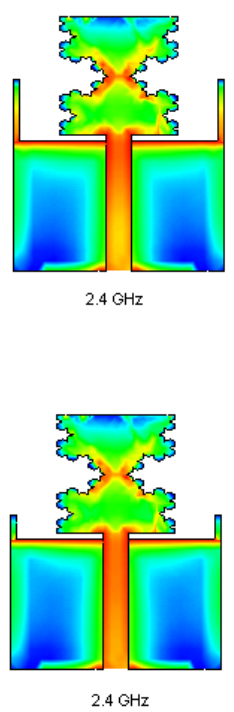

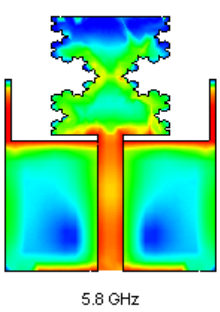

(a)

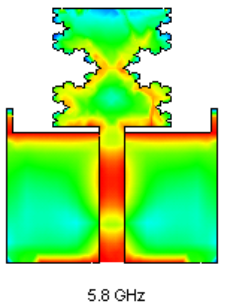

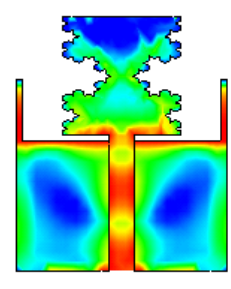

$7.0 \mathrm{GHz}$

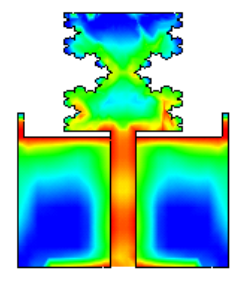

$7.0 \mathrm{GHz}$
Figure 12: The surface current distributions on the 3rd iteration Koch fractal monopole antenna structures for (a) $\mathrm{U}=10 \mathrm{~mm}$, and $\mathrm{U}=4 \mathrm{~mm}$.

The proposed antenna performance has been compared with those reported in the recently published literature. For

Table 1. Comparison with the recently published literature

\begin{tabular}{llclll}
\hline Ref. & size $\left[\mathrm{mm}^{3}\right]$ & No. of Res. bands & Res. freq. $(\mathrm{GHz})$ & Bandwidths $(\%)$ & Gain $(\mathrm{dB})$ \\
\hline$[4]$ & $50 \times 50 \times 1.6$ & 2 & $2.4 / 5.8$ & $42 / 20$ & $3.2 / 4.3$ \\
\hline$[11]$ & $30 \times 24.4 \times 1.6$ & 4 & $3.1 / 5.52 / 7.31 / 9.72$ & $3.5 / 5.01 / 13.2 / 5.77$ & $1.35 / 1 / 1.07 / 1.75$ \\
\hline$[20]$ & $27 \times 16 \times 1.6$ & 2 & $2.4 / 5.2$ & $12.5 / 4.1$ & $3.02 \times 3.25$ \\
\hline$[21]$ & $40 \times 40 \times 1.6$ & 3 & $1.5 / 3.5 / 5.4$ & $1.9 / 14 / 5$ & $-4.5 / 3.75 / 5.3$ \\
\hline$[22]$ & $18.8 \times 20 \times 0.76$ & 2 & $2.4 / 5.2$ & $1.6 / 23$ & $-1.7 / 2.4$ \\
\hline$[23]$ & $34 \times 18 \times 1.6$ & 3 & $2.5 / 3.5 / 5.5$ & $8.7 / 8 / 24.1$ & $-0.10 / 0.59 / 4.76$ \\
\hline$[24]$ & $100 \times 100 \times 0.8$ & 2 & $3.3 / 4.2$ & $12.1 / 4.8$ & $3.4-7.2 / 2.2-7.8$ \\
\hline$[25]$ & $50 \times 50 \times 1.0$ & 2 & $2.4 / 5.8$ & $45.9 / 12.7$ & $1.62-3.1 / 1.74-3.78$ \\
\hline Prop. & $40.7 \times 33.4 \times 1.6$ & 2 & $2.4 / 5.8$ & $54.52 / 11.80$ & $1.9-2.8 / 5.20-5.65$ \\
\hline
\end{tabular}


this purpose, Table 1 demonstrates many performance parameters of many dual-band and multiband antennas produced by various design methodologies. Among these parameters, a particular emphasis is concentrated on the realized bandwidths and the compactness offered by the proposed antenna as it is considered the main contribution in the present work. In this respect, the proposed antenna has shown to provide a reasonable degree of miniaturization.

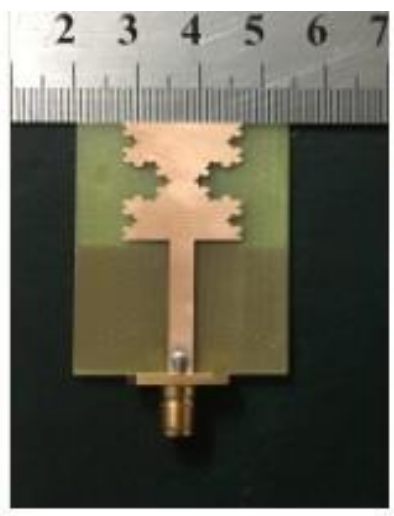

(a)

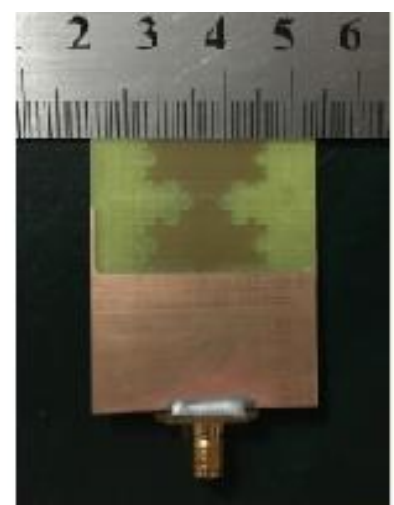

(b)
Figure 13. Photos of the fabricated antenna prototype; (a) the top view and (b) the bottom view.

Table 2. Summary of the fabricated antenna dimensions in $(\mathrm{mm})$

\begin{tabular}{cc}
\hline Parameter & Value $(\mathrm{mm})$ \\
\hline $\mathrm{L}$ & 18.93 \\
\hline $\mathrm{W}$ & 18.93 \\
\hline $\mathrm{G}$ & 0.95 \\
\hline $\mathrm{h}$ & 20.71 \\
\hline $\mathrm{GRD}$ & 33.50 \\
\hline
\end{tabular}

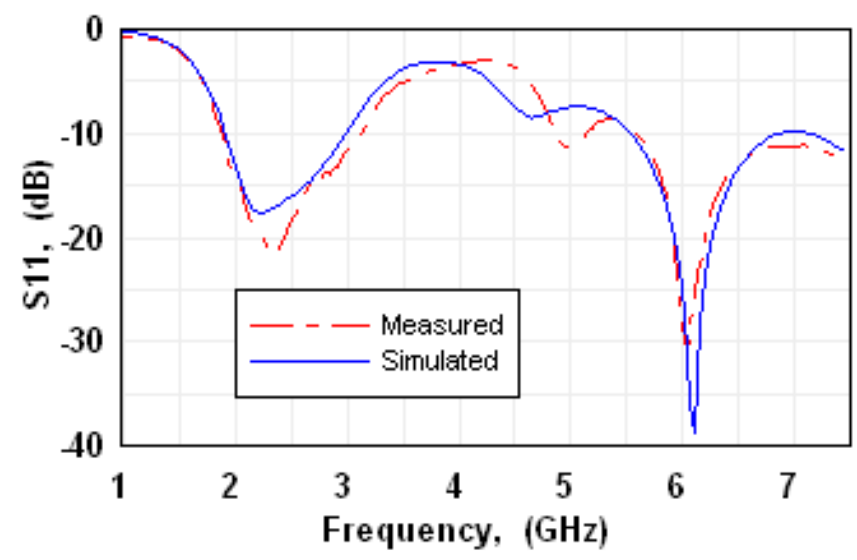

Figure 14. The measured and simulated input reflection coefficient responses of the fabricated prototype

The antenna structure depicted in Figure 6(b) has been fabricated using an FR-4 substrate with a thickness of 1.6 $\mathrm{mm}$ and a relative dielectric constant of 4.4. Figure 13 shows the photos of the fabricated prototype. The photo presented in Figure 15 shows the setup of the input reflection coefficient measuring using the VectorStar ME7838A broadband vector network analyzer from Anritsu. The dimensions of the fabricated prototype are demonstrated in Table 2. The size of the resulting antenna is $33.5 \times 40.70$ $\mathrm{mm}^{2}$. This size corresponds to $0.35 \lambda_{\mathrm{g}} \times 0.42 \lambda_{\mathrm{g}}$, where is $\lambda_{\mathrm{g}}$ calculated at the lower resonant frequency. The measured results of the input reflection coefficient response of the fabricated prototype agree well with those predicted by simulation as shown in Figure 14. The measured results of Figure 14 reveal that the antenna offers two resonant bands throughout the swept frequency range. The first band, centered at $2.78 \mathrm{GHz}$, extends from $1.72-3.18 \mathrm{GHz}$ with a fractional bandwidth of $52.51 \%$. The second resonant band covers a frequency range from $5.53-6.25 \mathrm{GHz}$, and centered at $6.10 \mathrm{GHz}$ with a fractional bandwidth of $11.80 \%$.

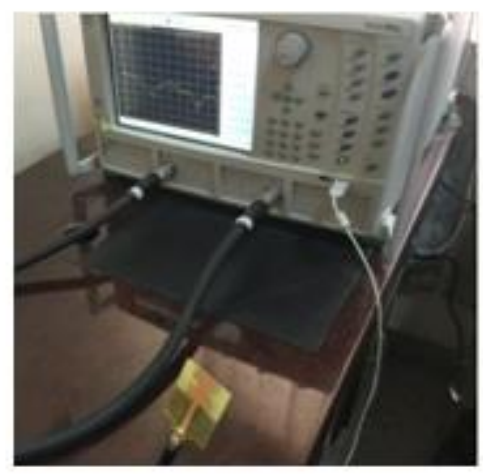

Figure 15. A photo showing the fabricated antenna input reflection coefficient measurement setup
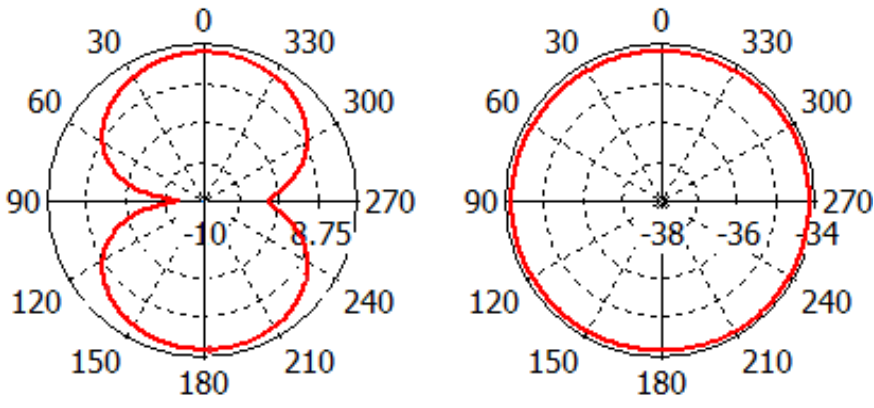

(a)
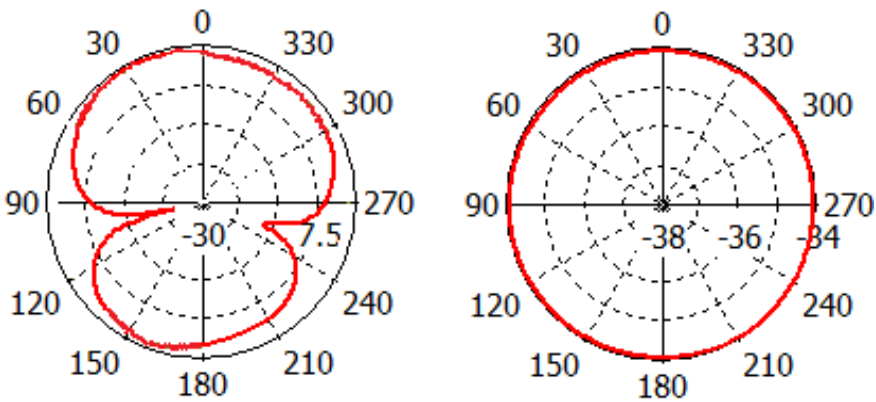

(b)

Figure 16. Simulated far-field radiation patterns of the proposed antenna at: (a). $2.4 \mathrm{GHz}$ and (b). $5.8 \mathrm{GHz}$. 
Figure 16 shows the simulated far-field radiation patterns of the proposed antenna at 2.4 and $5.8 \mathrm{GHz}$. It is clear that the radiation patterns thoroughly agree with those predicted for the traditionally printed monopole antenna. The radiation patterns, presented in the figure at the centers of the two resonant bands, show omnidirectional patterns in the horizontal plane, and a figure-eight in the perpendicular plane.
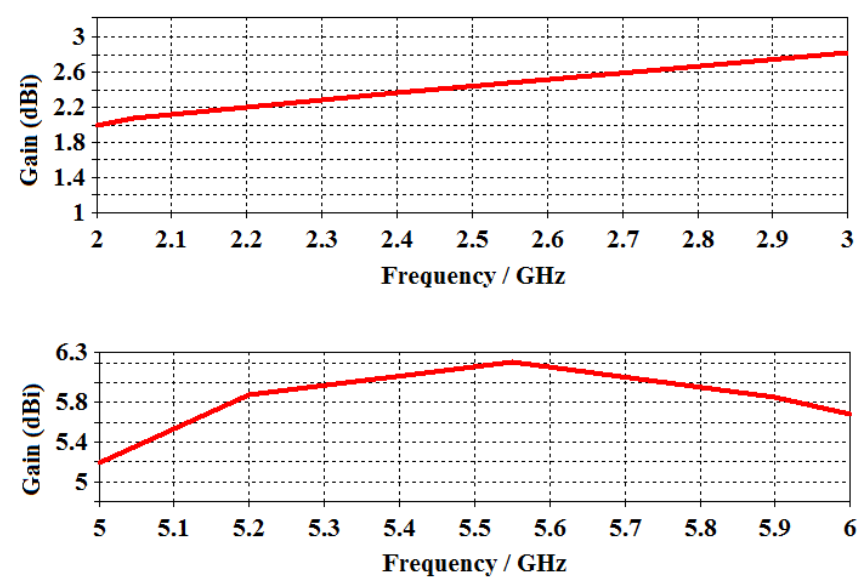

Figure 17. Computed peak gains of the proposed antenna throughout the lower and the upper resonant bands

Figure 17 demonstrates the peak gain responses throughout the two resonant bands. The antenna offers a gain in the range of 1.9-2.8 $\mathrm{dBi}$ throughout the lower resonant band, and about 5.20-5.65 $\mathrm{dBi}$ throughout the upper band. These values of the gain makes the proposed antenna competes with those reported in Table 1.The calculated values of the antenna efficiencies at the centers of the upper and the lower bands are $88 \%$ and $78 \%$ respectively.

\section{Conclusions}

A compact dual-band printed monopole antenna has been investigated and thoroughly analyzed in this paper. The proposed antenna size reduction has been carried out on the radiating antenna element and the width of its ground plane. The size reduction of the radiating antenna element is achieved by applying the Koch fractal geometry of the 3rd iteration to the radiator sides. Besides, the antenna ground plane has been virtually extended without the addition of an extra size making the antenna larger. The edges of the antenna ground plane are provided with conducting stubs that are practically equivalent to a ground plane extension. The suggested antennas have been evaluated using a method of moments, MoM-based EM simulator, IE3D. A conducted parametric study reveals that the antenna will have an exciting performance with a considerable ratio of the upper to the lower resonant frequencies making it suitable for integration of many of the recently available dual-band communication services. Measured results reveal that the antenna offers two resonant bands. The first band, centered at $2.78 \mathrm{GHz}$, extends from $1.72-3.18 \mathrm{GHz}$. The second resonant band covers a frequency range from 5.536.25 GHz. Consequently, the proposed antenna might be suitable to cover many operating bands of the wireless communication systems (2.4 GHz-Bluetooth, $2.4 \mathrm{GHz}$ ISM, 2.4/5.8 GHz-WLAN, 5.8 GHz-ITS).

\section{Acknowledgment}

The authors would like to express their thanks to the Engineers Ghaleb N. Najm, Mahmood R. Muhsen, Ahmed J. Qasim from the Industrial R\&D Administration, Ministry of Science and Technology, Iraq for providing the fabrication and measuring facilities.

\section{References}

T. Ali, S. Pathan, R. C. Biradar, Multiband, frequency reconfigurable, and metamaterial antennas design techniques: Present and future research directions, Internet Technology Letters, 2018 https://doi.org/10.1002/itl2.19

B. B. Mandelbrot, The Fractal Geometry of Nature, San Francisco, CA: W. H. Freeman, 1982.

J. Gouyet, Physics and Fractal Structures, New York: Springer, 1996.

J. K. Ali, S. Abdulkareem, A. Hammoodi, A. Salim, M. Yassen, M. Hussan, H. Al-Rizzo, Cantor fractal-based printed slot antenna for dual-band wireless applications, Int. J. of Microwave and Wireless Techn., 8: 263-270, 2016. https://doi.org/10.1017/S1759078714001469

D. D. Krishna, M. Gopikrishna, C. K. Anandan, CPW-fed Koch fractal slot antenna for WLAN/WiMAX applications, IEEE Ant. and Wireless Propag. Lett., 7: 389-392, 2008.

M. T. Yassen, M. R. Hussan, H. A. Hammas, H. Al-Saedi J. K. Ali, A compact dual-band slot antenna based on Koch fractal snowflake annular ring, Proc. of Prog. In Electromag. Res. Symp., St. Petersburg, Russia, pp. 670 $-674,2017$.

J. K. Ali, M. T. Yassen, M. R. Hussan, A. J. Salim, A printed fractal based slot antenna for multi-band wireless communication applications, Proc. of Prog. In Electromag. Res. Symp., Moscow, Russia, pp. 618 $622,2012$.

Ali, J. K., A. J. Salim, A. I. Hammoodi, H. Alsaedi, An ultra-wideband printed monopole antenna with a fractal based reduced ground plane, Proc. of Prog. In Electromag. Res. Symp., Moscow, Russia, pp. 613 617,2012

Ali, J.K. and Ahmed, E.S., A new fractal based printed slot antenna for dual band wireless communication applications, Proc. of Prog. In Electromag. Res. Symp., Kuala Lumpur, Malaysia, pp. 1518-1521, 2012.

Ali, J. K., Zaid A. A. AL-Hussain, A. A. Osman A. J. Salim, A new compact size fractal based microstrip slot 
antenna for GPS applications, Proc. of Prog. In Electromag. Res. Symp., Kuala Lumpur, Malaysia, pp. $700-703,2012$.

Ali, T., Saadh Aw, M., and Biradar, R., A fractal quad-band antenna loaded with L-shaped slot and metamaterial for wireless applications, Int. J. of Microwave and Wireless Technology, pp. 1-9, 2018. https://doi.org/10.1017/S1759078718000272 .

S. F. Abdulkarim, A. J. Salim, J. Ali, A. I. Hammoodi, M. T. Yassen, M. R. Hassan, A compact Peano-type fractal based printed slot antenna for dual-band wireless applications, Proc. RFM2013, Penang, Malaysia, pp. $329-332,2013$.

A. J. Salim, J. K. Ali, Design of internal dual band printed monopole antenna based on Peano-type fractal geometry for WLAN USB dongle, Proc. of Prog. In Electromag. Res. Symp., Suzhou, China, pp. 1268 1272, 2011.

S. F. Abdulkarim, A. J. Salim, A. I. Hammoodi, J. K. Ali, A fractal-based printed slot antenna for multi-band wireless applications, Proc. of Prog. In Electromag. Res. Symp., Stockholm, Sweden, pp. 1047 - 1051, 2013.

J. K. Ali, A new microstrip-fed printed slot antenna based on Moore space-filling geometry," Proc., LAPC 2009, Loughborough, U.K, pp. 449-452, 2009.

K. Xu, Z. Zhu, H. Li, J. Huangfu, C. Li, L. Ran, A printed single-layer UWB monopole antenna with extended ground plane stubs, IEEE Ant. and Wireless Propag. Lett. 12: 237-240, 2013.

M. T. Tan, B. Z. Wang, Z. Wang, H. Y. Huang, M. S. Liang, A novel compact CPW-fed UWB planar antenna with L-shaped extended ground plane stubs, Proc. IEEE APSURSI, pp. 207-208, 2014.

IE3D User's Manual, Zeland Software Inc., 2008.

H. Kogure, Y. Kogure, J. C. Rautio, Introduction to RF Design Using EM Simulators, Artech House Microwave Library, USA, 2010.

T. Ali, R. C. Biradar, A compact hexagonal slot dual band frequency reconfigurable antenna for WLAN applications, Microwave and Opt. Tech. Lett. 59: 958964, 2017. https://doi.org/10.1002/mop.30443

H. Rajabloo, V. A. Kooshki, H. Oraizi, Compact microstrip fractal Koch slot antenna with ELC coupling load for triple band application, AEU International Journal of Electronics and Communications, 73: 144-149, 2017. https://doi.org/10.1016/j.aeue.2016.12.027

A. A. Salih and M. S. Sharawi, A Dual-Band Highly Miniaturized Patch Antenna, IEEE Antennas and Wireless Propagation Letters, 15: 1783-1786, 2016. https://doi.org/10.1109/LAWP.2016.2536678

L. Li, X. Zhang, X. Yin and L. Zhou, "A Compact TripleBand Printed Monopole Antenna for WLAN/WiMAX Applications," in IEEE Antennas and Wireless Propagation Letters, 15: 1853-1855, 2016. doi: $\underline{10.1109 / \text { LAWP.2016.2539358 }}$
Snehalatha, L., N. Pathak, S. Manhas, reconfigurable multibeam dual-band antenna based on Vee dipoles. Advanced Electromagnetics, 7: 19-24, 2018. doi.org/10.7716/aem.v7i2.724

Fei, L., K. Xu, P. Zhao, L. Dong, and G. Wang, Uniplanar dual-band printed compound loop antenna for WLAN/WiMAX applications, Electronics Letters 53: 1083-1084, 2017. doi: 10.1049/el.2017.1543 